\title{
Cenplestao
}

\section{Remanescentes das Missões Jesuítico-Guaraní no Rio Grande do Sul: da pedra e cal à paisagem cultural}

\author{
Ana Lúcia Goelzer Meira \\ Doutora, Universidade do Vale do Rio dos Sinos, São Leopoldo, RS, Brasil; \\ algmeira@gmail.com \\ Leonardo Alberto Corá Silva \\ Mestre, Faculdade de Tecnologia - FTEC, Porto Alegre, RS, Brasil; \\ leonardocora@yahoo.com.br
}

Resumo: O patrimônio material e imaterial das Missões Jesuítico-Guarani, simbolizado pelas ruínas de São Miguel Arcanjo, recebeu todas as formas de reconhecimento patrimonial ao longo dos séculos XX e XXI: Monumento Histórico em nível estadual, Patrimônio histórico e artístico nacional, Patrimônio mundial, Patrimônio cultural do Brasil, Patrimônio cultural do Mercosul e, ainda, uma associação indireta ao título de Referência cultural brasileira. Este artigo busca refletir sobre a abrangência do processo de patrimonialização dos remanescentes missioneiros, a partir de uma revisão bibliográfica, propondo uma periodização direcionada a três componentes: a abordagem tradicional relacionada ao patrimônio material, a abordagem relacionada ao patrimônio imaterial, e a territorial, que passou a compreender os remanescentes como um sistema - a paisagem cultural missioneira. Este conceito embasou o projeto do Guia da Paisagem Cultural para o Desenvolvimento Sustentável das Missões, fruto da cooperação internacional entre Brasil e Espanha. As pesquisas realizadas para compor o Guia identificaram centenas de patrimônios culturais e naturais de interesse para a preservação, além dos remanescentes das antigas reduções. Patrimônios que foram construídos por novos agentes, como os imigrantes que chegaram a partir do século XIX. Esses aportes são coerentes com o conceito de paisagem cultural que, pela sua amplitude, agregou diversos municípios missioneiros em torno do projeto de valorização de um território, além de pressupor o diálogo entre distintos grupos sociais. Ainda que a execução do Guia tenha ficado inconclusa, originou a criação do Parque histórico nacional das Missões, e propiciou uma importante contribuição teórica e prática para as instituições brasileiras que participaram do processo.

Palavras-chave: Missões Jesuítico-Guaraní. Tava. Patrimônio cultural imaterial. Paisagem Cultural. 


\section{Introdução}

As Missões Jesuítico-Guarani que configuraram a Província Jesuítica do Paraguai, desenvolveram-se nos séculos XVII e XVIII, em territórios que hoje pertencem ao Brasil, Argentina, Paraguai e Uruguai. Durante muito tempo, as narrativas sobre essa experiência ocorrida sob o domínio da Coroa espanhola foram silenciadas por se contraporem à vertente lusitana da historiografia oficial brasileira. Assim, foi esvaziada de seus múltiplos significados, reduzindo-os a temas estéticos, no caso das ruínas dos templos missioneiros, à construção de mitos heroicos da resistência indígena, no caso da memória coletiva e, em geral, simplificando a complexa interação ocorrida entre os jesuítas impregnados pelo barroco europeu e a sociedade tribal dos indígenas latino-americanos.

Ainda que durante parte do século XX tenham sido menosprezados pelos historiadores tradicionais e por preservacionistas modernos (MEIRA, 2008), sete dos trinta povoados - os Sete Povos das Missões, que passaram a fazer parte do Rio Grande do Sul após o Tratado de Madri, foram precocemente contemplados por ações de preservação e também foram os patrimônios mais reconhecidos nas políticas públicas de preservação em nível estadual, nacional e internacional.

Trata-se de um dos primeiros lugares, no Brasil, onde as políticas públicas de preservação em relação ao patrimônio material e ao patrimônio imaterial se amalgamaram e possibilitaram a emergência de novas narrativas. Este artigo busca refletir sobre a abrangência desse processo, objetivando identificar e analisar períodos de inflexão na preservação do patrimônio Jesuítico-Guaraní sob o ponto de vista das categorias dos bens patrimoniais. Após a análise dos documentos e bibliografias disponíveis em meios eletrônicos, nos sites das instituições e em pesquisa realizada em arquivos, propõe-se uma periodização relacionada a três componentes: uma abordagem tradicional relacionada ao patrimônio material consubstanciado nos bens móveis e imóveis, uma abordagem relacionada ao patrimônio imaterial e uma territorial, que passou a compreender os remanescentes como um sistema - a paisagem cultural missioneira. 
A primeira compreende os tombamentos dos remanescentes dos antigos povos de São Miguel Arcanjo, São Lourenço Mártir, São João Batista, São Nicolau, o conjunto de imagens sacras de São Luiz Gonzaga e algumas imagens e peças que fazem parte do Museu Júlio de Castilhos, cujo acervo foi reconhecido como patrimônio histórico e artístico nacional. A segunda valoriza a cultura tradicional dos guaranis e o seu olhar sobre os remanescentes, que emergiram a partir do desenvolvimento do Inventário Nacional de Referências Culturais - INRC Comunidade Mbyá-Guarani em São Miguel Arcanjo. Resultou no Registro como Patrimônio cultural do Brasil da Tava em São Miguel Arcanjo. A terceira se refere à paisagem cultural dos vinte e seis municípios que compõem, atualmente, o que outrora era território das Missões ${ }^{1}$. Incorpora as novas contribuições dos grupos de imigrantes que ali se instalaram a partir do século XIX reconhecendo, assim, a diversidade cultural da região. Como parte inicial dessa abordagem territorial, o Instituto do Patrimônio Histórico e Artístico Nacional (IPHAN) instituiu o Parque nacional das Missões em 2009.

\section{A preservação do patrimônio cultural material nas Missões}

O sentido da preservação de um bem patrimonial ocorre em função da representação, evocação ou memória da qual ele é depositário, e não pela materialidade em si (SOUZA FILHO, 2006). Na origem latina do patrimonium, encontra-se uma associação com paterno e pátria, e, no campo do patrimônio cultural, o termo pressupõe herança e legado. Preservam-se os bens materiais ou imateriais portadores de referências para uma cultura. Para isso, realizam-se escolhas, que são embasadas em atribuição de valores (CARSALADE, 2014) e que variam com o tempo e o lugar. Geralmente, o saber técnico atribui valores históricos, artísticos, antropológicos, arqueológicos e outros, baseados no conhecimento científico. E os grupos sociais se mobilizam, na maioria das vezes, pelo valor afetivo, que é muitas vezes menosprezado nas instâncias oficiais. Pode-se questionar quem pode ou quem deveria fazer as escolhas, mas o poder da nomeação oficial é, no final, atribuição do Estado (BOURDIEU, 1992). 
No caso do Rio Grande do Sul, as análises técnicas e as percepções do senso comum convergem para um lugar: os antigos Sete Povos das Missões. Os remanescentes materiais missioneiros, constituídos por currais de pedra, vestígios de capelas e instalações residenciais, antigos postos de aferição, caminhos, poços e tanques, ruínas de algumas das reduções, imagens sacras e outros artefatos são encontrados dispersos em grande parte do território do estado, sendo que a maioria não é inventariada e nem protegida oficialmente. Sobre três dos sete povoados cresceram cidades - Santo Ângelo, São Luiz Gonzaga e São Borja. Os remanescentes de São Nicolau, no município de mesmo nome, e São Miguel Arcanjo, no atual município de São Miguel das Missões, encontram-se em áreas urbanas. Os de São Lourenço Mártir, no município de São Luiz Gonzaga, e São João Batista, no atual município de Entre-Ijuís, localizam-se em distritos rurais. Os quatro últimos sítios são propriedades da União e tombados pelo IPHAN - São Miguel Arcanjo nos anos 1930 e os demais em 1970. Além dos sítios, a coleção de imagens missioneiras da igreja matriz de São Luiz Gonzaga foi tombada em 1983, sendo que há imagens missioneiras no acervo tombado do Museu Júlio de Castilhos, cuja proteção ocorreu em 1938.

Nos anos 1920, as ruínas do antigo povo de São Miguel Arcanjo, no atual município de São Miguel das Missões, foram reconhecidas como Monumento Histórico pelo Governo do Estado. Em 1938, foram tombadas pelo IPHAN e, em 1983, declaradas Patrimônio Mundial pela Organização das Nações Unidas para a Educação, a Ciência e a Cultura (UNESCO), sendo que a Convenção para a Proteção do Patrimônio Mundial que consagrou os componentes culturais e naturais do patrimônio havia sido promulgada em 1972, ou seja, pouco mais de dez anos antes.

A preservação dos remanescentes materiais missioneiros é muito conhecida e estudada, com interpretações que mostram a construção de narrativas no Museu das Missões (BAUER, 2006), a natureza singular da arquitetura (CUSTÓDIO, 2002) e dos estabelecimentos urbanos (KERN, 2007). Muitos autores se dedicaram a estudar o povoamento do território, as experiências culturais, sociais e científicas (VIÑUALES, 2019; GUTIERREZ, 2013), as intervenções 
sobre as estruturas arquitetônicas (STELLO, 2005), o processo de patrimonialização das ruínas (MARCHI, 2018; MEIRA, 2019), os remanescentes arqueológicos ainda desconhecidos (SCHMITZ, 2018) e muitos outros aspectos que refletem a relevância do patrimônio material. Cabe ressaltar que as administrações municipais da região valorizam o legado missioneiro, embora não necessariamente se encarreguem de sua preservação. Esse interesse pode ser observado nos sites oficiais das municipalidades, sendo o de São Borja, o mais celebrativo:

Nesta terra ocorreu algo que jamais aconteceu em lugar algum, nativos e jesuítas criaram uma sociedade justa, igualitária e autossustentável, trata-se das Reduções Missioneiras. O que filósofo francês, Voltaire, chamou de 'Triunfo da Humanidade'. (HISTÓRIA, 2017a).

Centenas de estudos e publicações poderiam ser mencionados e, por haver tantas fontes de pesquisa disponíveis, o tema do patrimônio material das Missões não será aqui aprofundado. Basta dizer que o foco sempre incidiu no conhecimento e na preservação dessa categoria de patrimônio. Contudo, não se pode pensar que foram suficientes as proteções já realizadas, pois muitos sítios arqueológicos históricos e pré-históricos ainda são desconhecidos. Mesmo estruturas remanescentes importantes só foram descobertas recentemente, como por exemplo, a bem conservada casa de pedra no Passo do Aferidor, em Uruguaiana (VARGAS; SCHMITZ, 2015).

A extensão do patrimônio em nível internacional, a partir dos anos 1960, espraiou-se para novos temas como patrimônio industrial, comercial, vernacular e outros: a ampliação tipológica, cronológica e estilística identificada por Choay (2001). No Brasil, a ampliação do conceito de patrimônio começou a ser institucionalizada nos anos 1970 (ANDRADE JÚNIOR, 2011). Ainda novas significações se apresentaram no século XXI segundo Paez (2020).

Coloca-se, atualmente, o desafio de estender a proteção a artefatos, paisagens e arquiteturas representativas desses novos temas e, particularmente, dos períodos posteriores à presença Jesuítico-Guarani, tarefa que o Instituto do Patrimônio Histórico e Artístico do Estado (IPHAE) iniciou há poucos anos. Com o tempo, a noção de patrimônio "[...] emancipa-se mediante um interesse 
coletivo crescente pela preservação do patrimônio intangível." (BENHAMOU, 2016). E essa ampliação vai ser observada em São Miguel Arcanjo.

\section{A preservação do patrimônio imaterial nas Missões}

Dentre os sítios missioneiros remanescentes no Rio Grande do Sul, São Miguel Arcanjo é o que mais se configura como um lugar simbólico. Carsalade (2017) relaciona duas abordagens em relação ao conceito de lugar que se aplicam a esses remanescentes:

A primeira entende o 'lugar' como dotado de uma personalidade única e irreprodutível, a segunda aborda o 'lugar' do ponto de vista da sua relação com o fruidor, as duas levando ao conceito de pertencimento. (CARSALADE, 2017, p. 177)

A relação dos M'Byá Guarani com os remanescentes missioneiros, em São Miguel, está profundamente ligada a políticas públicas que institucionalizaram a preocupação com os bens imateriais no Brasil. Porém, no caso do Rio Grande do Sul, é relevante referir experiências anteriores.

Em 2003, a Unesco institucionalizou a salvaguarda do patrimônio imaterial que compreende "“[...] as práticas, representações, expressões, conhecimentos e técnicas - junto com os instrumentos, objetos, artefatos e lugares culturais que lhes são associados [...]." (UNESCO, 2014, p.5). Imaterial designa aquilo que não tem a natureza da matéria e, muitas vezes, é denominado de intangível ${ }^{2}$. Esses bens são reconhecidos pelas comunidades como portadores de significados, são constantemente recriados e transmitidos de geração em geração. Cumprem um papel fundamental que é promover o respeito à diversidade cultural em um mundo globalizado.

A primeira referência documentada no RS, até o presente, sobre o patrimônio imaterial, encontra-se na Carta cultural de São Miguel das Missões, resultante de uma reunião do Conselho Estadual de Cultura realizada no Museu das Missões nos anos 1970. A Carta expressa a necessidade de preservar "[...] tudo quanto se refira à cultura material e não material desta região brasileira, em especial do Estado do Rio Grande do Sul.” (RIO GRANDE DO SUL, [1974?], p.1). Tratava-se de uma manifestação conectada com a ampliação de conceitos 
relativos ao patrimônio cultural que vinham sendo experimentadas em nível nacional.

No final dessa década, consolidou-se, na Universidade de Caxias do Sul (UCS), o projeto de pesquisa dos Elementos culturais das antigas colônias italianas da região nordeste do Rio Grande do Sul (ECIRS). A equipe multidisciplinar partiu do entendimento de que a cultura é um processo de transformação permanente, profundamente relacionado com as identidades locais. E, no caso específico da região, resultante de trocas culturais que ocorreram

[...] entre a cultura - melhor seria talvez dizer as culturas, tal a diversidade de língua e de hábitos entre os imigrantes que vieram da Itália - trazida pelo imigrante com a cultura que já vinha sendo construída no Sul do Brasil. (RIBEIRO; POZENATO, 2004, p.15).

Durante quase três décadas, foram registradas as expressões materiais e imateriais das manifestações culturais na serra gaúcha: arquitetura, artefatos relacionados ao trabalho, mobiliário, usos e costumes, fábulas, rezas, ditados, canções, danças populares e outros, legando um dos mais importantes acervos de documentação sobre os imigrantes no Brasil.

A seguir, foi promovido em Porto Alegre o seminário A memória numa cidade democrática ${ }^{3}$, pela Secretaria Municipal da Cultura (SMC), quando foram definidas as diretrizes das políticas públicas para a preservação cultural no município: descentralização, educação patrimonial, construção das memórias e participação popular. Nesta última, estava implícita a responsabilidade de toda a sociedade e não só do saber especializado em relação à preservação, e sua abrangência pode ser percebida no entendimento de que:

[..] falar em patrimônio significa reportar-se para o campo das diferenciações, da pluralidade, da heterogeneidade e da consciência constitutiva das relações sociais e de seus produtos de múltiplos significados [...] não se restringem apenas ao que é material - bens culturais tangíveis - mas também ao que é intangível. (POSSAMAI, 2001, p. 162-163).

O primeiro caso que provocou debate público sobre a relação entre a materialidade e a imaterialidade de um bem cultural, no RS, ocorreu na $1^{\text {a }}$ Conferência Municipal da Cultura, em 1995. Uma das demandas aprovadas foi o 
tombamento do espaço de ação cultural denominado Terreira da Tribo, mantido pelo grupo de teatro Ói Nóis Aqui Traveiz. Sabe-se que havia um litígio em relação ao aluguel do imóvel, e o tombamento pareceu ser um argumento em favor da manutenção do uso cultural. No decorrer do processo, as manifestações das mais diferentes regiões da cidade em prol da sua preservação mostraram que o espaço tinha significados mais amplos e reconhecidos. Em sucessivas demandas junto ao Orçamento Participativo, nas plenárias regionais e temáticas, foram aprovadas resoluções destinadas à defesa do lugar ${ }^{4}$. Para aprofundar o debate, a Coordenação da Memória Cultural da Secretaria Municipal da Cultura (SMC) promoveu, em 1996, o Seminário nacional sobre a preservação e valorização dos bens culturais intangíveis: lendas, crenças, saberes e fazeres, histórias, tradições e costumes, processos de criação e fabricação ${ }^{5}$ (MEIRA, 2004). Por fim, o tombamento da Terreira da Tribo não foi realizado e o grupo mudou de endereço, levando consigo o nome do lugar.

No nível federal, um ano depois, durante as comemorações dos sessenta anos do IPHAN, realizou-se um seminário onde foram discutidas as formas de reconhecimento e valorização do patrimônio imaterial (SANT'ANNA, 2002) ${ }^{6}$. Foi instituído um grupo de trabalho que formulou as bases para o Decreto $\mathrm{n}^{\circ}$ 3551/2000, o qual instituiu o Registro dos bens culturais de natureza imaterial e criou o Programa Nacional do Patrimônio Imaterial (PNPI). Os bens registrados passaram a receber o título de Patrimônio Cultural do Brasil nas categorias celebrações, formas de expressão, saberes e lugares. O Inventário Nacional de Referências Culturais (INRC), parte do PNPI, começou a ser desenvolvido, em alguns estados, no início do século XXI, com o objetivo de produzir conhecimento sobre domínios da vida social com atribuição de valores e de sentidos para grupos formadores da sociedade brasileira.

No Rio Grande do Sul, as primeiras escolhas recaíram, não por acaso, sobre grupos sociais que, historicamente, nunca haviam sido valorizados nas políticas de preservação patrimonial: os negros e os indígenas. Foram desenvolvidos o INRC Massacre de Porongos, na região do município de Pinheiro Machado, e o INRC Comunidade M'Byá Guarani em São Miguel Arcanjo (PROJETOS, 2020). Uma demanda originada na Região de 
Colonização Italiana (RCI) do Rio Grande do Sul também pleiteou o reconhecimento do Talian $^{7}$ como patrimônio imaterial, tendo-se verificado a inadequação do INRC como meio de documentação e conhecimento das línguas. Foi então desenvolvido o Inventário Nacional da Diversidade Linguística (INDL). No estado, foram inventariados o Talian e o M’Byá Guarani, que receberam o título de Referência cultural brasileira.

O registro do patrimônio imaterial, em nível estadual, é regido pela Lei $\mathrm{n}^{\mathrm{o}}$ 13.678/2011, sob responsabilidade do IPHAE. E, no caso da capital, Porto Alegre, existe a Lei $n^{\circ}$ 9570/2004, cuja competência cabe à Secretaria Municipal da Cultura (SMC). Em ambos os casos, as legislações seguem a federal. A situação geral, nas três esferas da administração, em relação ao patrimônio cultural imaterial, encontra-se consolidada no Quadro 1.

Quadro 1 - Patrimônio imaterial inventariado e reconhecido no âmbito do Rio Grande do Sul

\begin{tabular}{|c|c|c|c|c|c|}
\hline \multirow{2}{*}{ Identificação } & \multirow{2}{*}{ Localização } & \multicolumn{2}{|c|}{ Referências Culturais } & \multicolumn{2}{|c|}{$\begin{array}{l}\text { Diversidade } \\
\text { Linguística }\end{array}$} \\
\hline & & inventário & registro & inventário & $\begin{array}{l}\text { reconheci- } \\
\text { mento }\end{array}$ \\
\hline $\begin{array}{l}\text { Comunidade } \\
\text { M'Byá } \\
\text { Guarani }\end{array}$ & $\begin{array}{c}\text { São Miguel das } \\
\text { Missões }\end{array}$ & IPHAN & $\begin{array}{l}\text { IPHAN } \\
\text { (Tava) }\end{array}$ & - & - \\
\hline $\begin{array}{l}\text { Comunidades } \\
\text { Remanescentes } \\
\text { do Quilombo } \\
\text { São Roque }\end{array}$ & Mampituba & IPHAN & - & - & - \\
\hline $\begin{array}{l}\text { Massacre de } \\
\text { Porongos }\end{array}$ & $\begin{array}{c}\text { Pinheiro Machado, } \\
\text { Caçapava do Sul, } \\
\text { Guaíba e Porto Alegre }\end{array}$ & IPHAN & - & - & - \\
\hline $\begin{array}{l}\text { Lidas } \\
\text { campeiras do } \\
\text { município de } \\
\text { Bagé }\end{array}$ & Bagé & IPHAN & - & - & - \\
\hline $\begin{array}{l}\text { Tradições } \\
\text { doceiras da } \\
\text { região de } \\
\text { Pelotas e } \\
\text { antiga Pelotas }\end{array}$ & $\begin{array}{l}\text { Pelotas, Arroio do } \\
\text { Padre, Capão do Leão, } \\
\text { Morro Redondo, } \\
\text { Turuçu }\end{array}$ & IPHAN & IPHAN & - & - \\
\hline $\begin{array}{l}\text { Ofício das } \\
\text { Baianas de }\end{array}$ & Brasil & IPHAN & IPHAN & - & - \\
\hline
\end{tabular}




\begin{tabular}{|c|c|c|c|c|c|}
\hline Acarajé $^{8}$ & & & & & \\
\hline $\begin{array}{l}\text { Roda de } \\
\text { Capoeira }\end{array}$ & Brasil & IPHAN & IPHAN & - & - \\
\hline $\begin{array}{l}\text { Ofício dos } \\
\text { Mestres de } \\
\text { Capoeira }\end{array}$ & Brasil & IPHAN & IPHAN & - & - \\
\hline $\begin{array}{l}\text { Língua } \\
\text { Guaraní } \\
\text { M'Byá }\end{array}$ & Diversos estados & - & - & IPHAN & IPHAN \\
\hline Talian & $\begin{array}{l}\text { Região de Colonização } \\
\text { Italiana }\end{array}$ & - & - & IPHAN & IPHAN \\
\hline $\begin{array}{l}\text { Bará do } \\
\text { Mercado }\end{array}$ & Porto Alegre & SMC & SMC & - & - \\
\hline Feira do Livro & Porto Alegre & SMC & SMC & - & - \\
\hline $\begin{array}{l}\text { Festa de } \\
\text { N.S.dos } \\
\text { Navegantes }\end{array}$ & Porto Alegre & SMC & SMC & - & - \\
\hline $\begin{array}{l}\text { Fundação } \\
\text { Orquestra } \\
\text { Sinfônica de } \\
\text { Porto Alegre } \\
\text { (OSPA) }\end{array}$ & Porto Alegre & SMC & SMC & - & - \\
\hline $\begin{array}{l}\text { Lendas } \\
\text { urbanas } 9\end{array}$ & Porto Alegre & SMC & SMC & - & - \\
\hline $\begin{array}{l}\text { Complexo da } \\
\text { erva mate }\end{array}$ & RS & $\begin{array}{c}\text { em } \\
\text { elaboração }\end{array}$ & - & - & - \\
\hline $\begin{array}{l}\text { Modo de fazer } \\
\text { queijo } \\
\text { artesanal } \\
\text { serrano }\end{array}$ & $\begin{array}{l}\text { Campos de Cima da } \\
\text { Serra }\end{array}$ & $\begin{array}{c}\text { em } \\
\text { elaboração }\end{array}$ & - & - & - \\
\hline
\end{tabular}

Fonte: Elaborado pelos autores.

Nota-se que há duas referências a componentes imateriais relacionados com as missões: o reconhecimento da língua Guarani M’Byá e o INRC Comunidade M’Byá Guaraní em São Miguel das Missões, que resultou no Registro da Tava - Lugar de referência para o povo Guaraní em São Miguel Arcanjo (CASARA, 2014). Para os guaranis, essa Tava "[...] por estar em ruínas, é uma metáfora da vida na terra de imperfeição, onde tudo é perecível.” 
(FREIRE; MEIRA, 2019, p.90) e, além disso, serve para mostrar ao homem branco o seu modo de vida. Os guaranis definiram como

[...] fundamental a adoção de sua perspectiva sobre a Tava no tratamento dispensado ao sítio de São Miguel Arcanjo, que assim deixará de ser o lugar de seu esquecimento, para tornar-se um lugar de pertencimento. (CASARA, 2014, p.12).

Segundo a autora, esse princípio deverá estar presente na gestão do Parque Histórico Nacional das Missões. No entanto, há que se superar o senso comum sobre os guaranis, como pode ser constatado no site da Prefeitura Municipal de São Miguel das Missões:

O antigo povo de São Miguel, localizado em São Miguel das Missões sobressai com o mais importante remanescente da civilização jesuítico guarani dos Sete Povos das Missões, [...] Nesta época [século XVII] inicia-se um período de grande desenvolvimento e num processo de transculturação os índios guarani vão gradualmente absorvendo a cultura europeia, transformando-se em hábeis artífices, metalúrgicos, tipógrafos, escultores, pintores, músicos. Ceramistas, canteiros e fabricantes de instrumentos musicais. (HISTÓRIA, 2017b).

Kern (2007, p. 1) faz referência a "duas fortes tradições culturais", o que induz a pensar sobre uma tensão constante entre as duas, em permanente processo de trocas e negociações, mas não sendo uma subalterna à outra. A participação dos guaranis nas manifestações artísticas, mais especificamente na escultura, como observa Sustersic (2013), não pode ser classificada como mera reprodução, pois possibilitou novas sínteses criativas. Importante para a própria sobrevivência das reduções missioneiras, a mitologia dos M'Byá revela, ainda hoje, um profundo conhecimento sobre a existência humana e sobre a natureza, especialmente sobre as regiões que fazem parte da sua territorialidade (SOUZA, 2007) o que, certamente, ajudou os jesuítas a sobreviverem na selva.

O reconhecimento mais recente da dimensão imaterial do patrimônio missioneiro foi a certificação como Patrimônio cultural do Mercosul, realizada em 2018, durante o XVII Encontro da Comissão do Patrimônio Cultural do Mercosul (PEREIRA, 2018). E os guaranis passaram a ter suas narrativas incorporadas ao sítio, não sem resistência por parte de alguns técnicos arquitetos. 


\section{A preservação da paisagem cultural missioneira}

As pautas preservacionistas atuais indicam que não é mais suficiente preservar o patrimônio material por meio do tombamento ou o imaterial por meio do registro, assim como depender exclusivamente da tutela das instituições ${ }^{10}$. $\mathrm{O}$ envolvimento das comunidades e a aproximação com o tema do desenvolvimento sustentável se apresentam como estratégias importantes (CASTRIOTA, 2009). Também não é suficiente preservar edificações, lugares, manifestações culturais ou paisagens de forma isolada. Em 1992, a UNESCO inseriu a paisagem cultural como categoria para a inscrição de sítios onde a relação entre a natureza e a sociedade apresentasse um valor universal excepcional. Buscava-se superar a dicotomia presente na Convenção do Patrimônio Mundial entre a conservação da natureza e a preservação do patrimônio cultural (RIBEIRO, 2020).

Essas dimensões se encontram expressas na portaria que instituiu a Chancela da Paisagem Cultural Brasileira, a qual reconhece o caráter dinâmico das relações entre a ação humana e o território, as transformações inerentes ao desenvolvimento sustentável, bem como a gestão compartilhada pelo poder público, sociedade civil e iniciativa privada (IPHAN, 2009). Não apenas o território sofreu alterações, mas o ser humano também, tendo sua cultura transformada pelo meio ambiente natural (RIBEIRO, 2007).

A formulação de um conceito de paisagem cultural adequado à realidade brasileira foi decorrente do evento comemorativo ao Dia do Patrimônio em $2007^{11}$. A Carta de Bagé: Carta da Paisagem Cultural define que paisagem cultural é o bem mais "amplo, completo e abrangente de todos, que pode apresentar todos os bens indicados pela Constituição" (CARTA, 2007, p.1). O texto, cujo artífice foi o arquiteto Carlos Fernando de Moura Delphim, especialista em jardins históricos no IPHAN, faz referência à participação deliberativa das comunidades locais e à necessidade de estabelecer um conselho local com ampla representatividade. Cabe ressaltar que no preâmbulo da Carta há referência à preservação do Bioma Pampa e, particularmente, à região missioneira: "O exemplo do passado registrado em territórios como o das 
Missões deve ser preservado e valorizado de forma integrada com nossos vizinhos" (CARTA, 2007, p.1).

Essa referência não foi casual, pois já existia, nessa época, no âmbito do patrimônio cultural, uma ampliação do olhar em relação ao território missioneiro e às narrativas indígenas. Partindo dos quatro sítios históricos isolados, passouse, aos poucos, à compreensão de que se tratava de um sistema. Em parecer sobre o projeto paisagístico de São Miguel Arcanjo, em 2003, disse Delphim que:

O conceito de paisagem é comumente confundido com o de sítio. Sítio é um lugar; paisagem, um sistema. Um sistema altamente complexo, dinâmico, diversificado e entrópico. Quanto mais amplos os domínios do território histórico das Missões, maior a integração com o sistema natural e geográfico regional. (DELPHIM, 2009a, p. $55)$.

$\mathrm{O}$ arquiteto destacou a necessidade da proposta paisagística se expandir para além do sítio de propriedade federal e se estender à área urbana circundante. Retornando ao sítio, posteriormente, ampliou seu posicionamento, ao sugerir a valorização das áreas rurais de cultivos diversos " [...] tanto na definição do perímetro de tombamento ou do entorno de sítios históricos ou paisagísticos, quanto em inventários de bens culturais." (DELPHIM, 2009b, p. 131). Notável é a reverência com que se refere aos guaranis e ao seu conhecimento empírico sobre a flora e a fauna, bem como a crítica dirigida ao olhar técnico reducionista.

Amplos estudos sobre o patrimônio natural e cultural na região foram iniciados em 2004, quando o Instituto Andaluz do Patrimônio Histórico $(\text { IAPH })^{12}$ e o IPHAN firmaram um Termo de Cooperação que deu guarida ao projeto integrado de valorização do patrimônio missioneiro. Trata-se do primeiro projeto no país que teve como base, desde o seu início, um conceito de paisagem cultural, neste caso baseado nos preceitos da Unesco e da União Europeia. A metodologia já havia sido empregada pelo IAPH e, tendo em vista que não havia outro precedente no Brasil, é relevante fazer uma sucinta descrição do processo ${ }^{13}$. Não se tratava de simples transferência de metodologia. Foi necessária uma adaptação entre as equipes espanholas e brasileiras, assim 
como muitas reuniões visando à integração com gestores e grupos sociais foram realizadas nos municípios da região.

O IAPH possui em sua estrutura um Laboratório da Paisagem Cultural com experiência em levantamentos e análises para designação de paisagens culturais, tanto rurais quanto urbanas. Compreende análises do meio físico, dos processos históricos, das atividades características dos espaços e das manifestações de autorrepresentação dos andaluzes. Para a preservação dessas paisagens foram desenvolvidos dois instrumentos: o Registro das Paisagens de Interesse Cultural $^{14}$, destinado ao conhecimento das paisagens da Andaluzia, que leva em conta a autenticidade dos significados, a integridade dos valores e o seu reconhecimento por parte das instituições e da sociedade (FERNÁNDEZ CACHO, 2018). E o Guia da Paisagem Cultural, que envolve etapas de identificação, por meio de pesquisas multidisciplinares nos campos da geologia, biologia, história, arquitetura, história da arte, urbanismo, sociologia e outras, e de planejamento das paisagens, que se propõe a construir consensos entre diversos setores da sociedade (FERNÁNDEZ CACHO, 2010) ${ }^{15}$.

$\mathrm{Na}$ região missioneira, foi proposto o desenvolvimento de um Guia da Paisagem Cultural para o Desenvolvimento Sustentável das Missões. Metodologicamente, tratava-se de um marco integrador composto por projetos setoriais: Estudo do potencial do desenvolvimento turístico da região, com levantamento dos recursos patrimoniais culturais e naturais; Exploração magnética no sítio arqueológico de São Miguel Arcanjo; Valorização do mundo cultural Guarani; Investigação histórico-artística da coleção do Museu das Missões e Avaliação da capacidade de carga dos sítios tombados (SALMERÓN, 2008). O entendimento sobre o patrimônio incorporava as categorias dos bens materiais, imateriais, paisagísticas em uma dimensão territorial, bem como introduzia a pauta da sustentabilidade econômica e social. O IPHAN contratou a Universidade Regional Integrada do Alto Uruguai e das Missões (URI) para realizar o extenso levantamento dos bens patrimoniais e naturais ${ }^{16}$, sendo que a descrição desse processo se encontra em Stello (2013). Uma equipe da Universidade Complutense de Madrid desenvolveu a pesquisa e o diagnóstico dos recursos turísticos (SALMERÓN, 2008). 
O patrimônio cultural missioneiro é entendido, geralmente, de maneira restrita aos remanescentes da experiência dos jesuítas e guaranis. Porém, o inventário dos recursos patrimoniais culturais e naturais realizado permitiu identificar centenas de patrimônios construídos por novos agentes, como os imigrantes que chegaram a partir do século XIX. Paisagens, edificações, ruínas, costumes, tradições, identificaram a influência dos países de origem desses novos aportes. Demonstrou-se a diversidade e complexidade da região que deram origem aos mapas de distribuição dos recursos patrimoniais, das tipologias patrimoniais, de relevância dos recursos patrimoniais culturais e naturais, os quais podem ser consultados em Salmerón (2008). A região foi, finalmente, tratada como um sistema.

Evidenciou-se a importância mas também a invisibilidade atual dos indígenas. No senso comum, os guaranis teriam sido exterminados na Guerra Guaranítica, restando apenas o mítico personagem de Sepé Tiarajú na memória coletiva. Mas milhares de guaranis sobreviveram, continuaram a viver em aldeias ou se miscigenaram. Nesse sentido, foi fundamental a proposta do projeto de Valorização do Mundo Cultural Guarani. O INRC Comunidade M’Byá Guarani em São Miguel das Missões pode ser estendido a outros estados brasileiros onde havia a presença de aldeias M'Byá (SC, PR, SP, RJ, ES). A viabilização se deu por meio do aporte financeiro do IPHAN e da Agência Espanhola de Cooperação Internacional e Desenvolvimento (AECID), que também colaborou em outras iniciativas como a realização do Encontro Internacional sobre Patrimônio Cultural e Povos Indígenas, o início do projeto Vídeo nas Aldeias para capacitação dos jovens M'Byá no uso de equipamentos e produção de vídeos, a realização de oficinas de fomento ao artesanato tradicional e a formação de guias de turismo indígenas. Essas demandas haviam sido formuladas pelos próprios guaranis.

Decorrente do desenvolvimento do Guia foi oficializado, em 2009, o Parque Histórico Nacional das Missões, na reestruturação regimental do IPHAN $^{17}$. Houve contestação ao projeto de lei de criação do Parque, pois já existia a figura dos parques nacionais voltados à preservação do meio ambiente $^{18}$. A proposta não foi oficializada limitando-se, na prática, a substituir 
o Escritório Técnico das Missões existente. Mas a disputa não é semântica e, se fosse efetivamente implantado, o Parque Histórico poderia ter um papel articulador importante na região, ao superar a visão burocrática e o olhar técnico reducionista a que se referia Delphim (2009b). Ao agregar a dimensão histórica, seriam priorizados os espaços em que as relações culturais fossem protagonistas, articulando bens naturais e culturais - materiais e imateriais, diferenciando-se dos parques naturais existentes. Buscava-se

[...] compreender como estas relações se deram ao longo do processo histórico de ocupação do território e como se traduzem nos dias de hoje. [...] A criação do Parque, a par da continuidade da conservação física dos remanescentes nos quatro sítios [São Miguel Arcanjo, São Nicolau, São Lourenço Mártir e São João Batista], é a garantia do aprofundamento das questões antropológicas relacionadas à presença dos diversos grupos sociais existentes na região. Nisto estão implicados tanto os grupos indígenas que ali transitam quanto os demais contingentes sociais que ali se estabeleceram para viver, reconhecendo e valorizando as suas formas de expressão, os seus saberes e fazeres, as suas celebrações e os seus lugares de referência para as suas práticas sócio-culturais. (BRASIL, 2006, p.1).

Em 2009, os estudos com vistas à elaboração do Guia da Paisagem Cultural para o Desenvolvimento Sustentável das Missões foram interrompidos devido ao contingenciamento dos recursos destinados a essa ação no orçamento do IPHAN-RS. Muitos levantamentos e análises que, devido à diversidade de profissionais e equipamentos necessários, teriam de ser contratados pela Instituição, não foram viabilizados. As tratativas de articulação com os grupos sociais foram interrompidas e o trabalho não se completou. Na realidade, houve um movimento por parte do Departamento do Patrimônio Material (DEPAM) do Instituto, na época, no sentido de reforçar a designação dos roteiros culturais da imigração de Santa Catarina para se constituir na primeira paisagem cultural brasileira oficialmente reconhecida.

De fato, dois anos depois, durante a reunião do Conselho Consultivo do IPHAN que aprovou o processo de Complementação do Tombamento das Edificações e Núcleos Urbanos e Rurais em Santa Catarina, surgiu a proposta de que o próprio processo originasse a Chancela da Paisagem Cultural (IPHAN, 2009), e foi aprovado o parecer no sentido da 
[...] abertura de procedimento especifico para concessão da chancela de Paisagem Cultural a todas as Edificações e Núcleos Urbanos e Rurais Relacionados com a Imigração em Santa Catarina. (IPHAN, 2011, p. 23).

Ou seja, a instrução do processo de tombamento serviria para instruir o processo de Chancela, equiparando, assim, os bens edificados urbanos e rurais à complexidade de uma paisagem cultural. Não foi mencionado que para a validação da paisagem cultural se faz necessário contemplar a relação recíproca e dinâmica entre os seres humanos e a natureza, possibilitando leituras espaciais e temporais como transmitem a Carta de Bagé e a portaria da Chancela.

Essa postura leva ao questionamento acerca da real compreensão sobre o conceito de paisagem cultural pelas instituições, o que pode ser estendido a alguns pesquisadores. As concepções clássicas em torno da preservação do patrimônio ainda estão vigentes quando se considera que a simples somatória de bens edificados, isolados ou em conjuntos, as paisagens capturadas pelos seus aspectos pitorescos, e os saberes culturais isolados possam constituir uma paisagem cultural. Da mesma forma, a imprescindível abordagem da gestão integrada e da participação das comunidades locais passa ao longe de algumas pesquisas que se propõem a enfrentar esse conceito tão dinâmico e complexo.

Por vezes, reduz-se a paisagem cultural a uma colagem de imagens de edificações, plantações, fogões a lenha, flores, pássaros, paisagens bucólicas, enfim, fragmentos da totalidade que poderia compor essa paisagem, mas sem as complexas relações que as compõem. São paisagens culturais esvaziadas de sentido, reduzidas aos seus aspectos pitorescos. Essas abordagens fracionadas, apenas ancoradas no território, empalidecem frente à profundidade das reflexões propostas pelo IAPH, justamente pela pluralidade de disciplinas que são demandadas no inventário das paisagens culturais e que, infelizmente, não puderam se completar no caso das Missões.

\section{Considerações finais}

As políticas de preservação do patrimônio cultural, ao longo de décadas, evoluíram da concepção de bem patrimonial reconhecido em sua individualidade para uma visão ampla que buscou articular patrimônio material 
e imaterial, e incorporou a dimensão da paisagem e do território. Em relação às Missões, que hoje compreendem os territórios de vinte e seis municípios, podese dizer que desde a pedra e cal dos preservacionistas pioneiros (alcunha devido à ênfase na proteção das edificações do período colonial brasileiro) à Tava (marca terrena para orientar a caminhada dos M’Byá Guarani), foi um percurso longo em busca de novas narrativas sobre a experiência missioneira que explicitou a dilatação de conceitos e de amplitudes.

As pesquisas sobre a experiência missioneira em diversos campos do conhecimento se intensificaram no século XXI, fomentando publicações, encontros, seminários, congressos nacionais e internacionais. Além dos historiadores e arquitetos, somaram-se arqueólogos, paisagistas, biólogos, antropólogos, etnólogos, geógrafos, turismólogos, museólogos, historiadores da arte e outros profissionais. Concomitante a esse processo, o entendimento sobre os bens patrimoniais e as formas de preservá-los passou a incorporar, além da abordagem técnica, a participação social e política decorrente da valorização do seu legado cultural. E superou sua dimensão de sítios isolados para serem pensados como um sistema articulado.

O patrimônio material e imaterial das Missões, simbolizado pelas ruínas de São Miguel Arcanjo, recebeu todas as formas de reconhecimento e valorização patrimonial ao longo de muitas décadas: considerada Monumento Histórico em nível estadual (patrimônio material), tombadas como Patrimônio Histórico e Artístico Nacional (patrimônio material), nomeadas como Patrimônio Mundial pela Unesco (patrimônio material), registrada como Patrimônio Cultural do Brasil (patrimônio imaterial), associada ao reconhecimento como Referência Cultural Brasileira (patrimônio linguístico) e Patrimônio Cultural do Mercosul (patrimônio imaterial).

A relevância da experiência Jesuítico-Guarani e sua influência sobre a formação cultural do estado, com o tempo, recebeu novas contribuições, enriqueceu-se e se diversificou. É fundamental que o reconhecimento dessas contribuições se aprofunde, se amplie e se institucionalize, englobando patrimônios ainda não consagrados. As novas estratégias em relação à preservação da região devem incrementar a participação dos grupos que ali 
habitam, na busca de uma gestão compartilhada que admita as transformações intrínsecas ao desenvolvimento econômico e social sustentáveis. Isso exigirá o fortalecimento das instituições e, por outro lado, sua abertura em relação à sociedade. Assim, talvez, no futuro, o território missioneiro, ou parte dele, possa vir a ser chancelado como Paisagem Cultural Brasileira.

\section{Referências}

ANDRADE JÚNIOR, Nivaldo Vieira. Ampliações do conceito de patrimônio edificado no Brasil. In: GOMES, Marco Aurélio A. de Filgueira; CORRÊA, Elyane Lins. (org.). Reconceituações contemporâneas do patrimônio. Salvador: Ed. UFBa, 2011. p. 145-165.

BAUER, Letícia. O arquiteto e o zelador: patrimônio cultural, história e memória - São Miguel das Missões (1937-1950). Dissertação (Mestrado em História)- Programa de Pós-Graduação em História, Universidade Federal do Rio Grande do Sul, Porto Alegre, 2006.

BENHAMOU, Françoise. Economia do patrimônio cultural. São Paulo: SESC, 2017.

BOURDIEU, Pierre. A economia das trocas simbólicas. 3 ed. São Paulo: Perspectiva, 1992.

BRASIL. Ministério da Cultura. Exposição de Motivos. Destinatário: Presidente da República. Brasília, outubro de 2006. Minuta provisória da Exposição de Motivos, sem numeração.

CARSALADE, Flávio de Lemos. A pedra e o tempo: arquitetura como patrimônio cultural. Belo Horizonte: Editora UFMG, 2014.

CARTA de Bagé: Carta da Paisagem Cultural. Bagé, 2007. Documento avulso não publicado.

CASARA, Carla Maria. Parecer sobre o Registro da TAVA MIRI SÃO

MIGUEL ARCANJO - Lugar de Referência para os Guaraní (Processo IPHAN nº 01450.016457/2007-85). Brasília: IPHAN, 2014.

CASTRIOTA, Leonardo. Paisagem Cultural e Técnicas Agrícolas Tradicionais: Preservação e Sustentabilidade no Serro (MG). In: CASTRIOTA, L (org.).

Paisagem Cultural e sustentabilidade. Belo Horizonte: UFMG, 2009.

CHOAY, Françoise. A alegoria do patrimônio. São Paulo: Estação Liberdade: Editora UNESP, 2001. 
CUSTÓDIO, Luiz Antônio B. A redução de São Miguel Arcanjo: contribuição ao estudo da tipologia urbana missioneira. 2002. Dissertação (Mestrado em Planejamento Urbano e Regional) - Programa de Planejamento Urbano e Regional, Universidade Federal do Rio Grande do Sul, Porto Alegre, 2002.

DELPHIM, Carlos Fernando M. A beleza e a harmonia da paisagem: parecer sobre a paisagem de São Miguel Arcanjo - São Miguel das Missões. In: DELPHIM, Carlos Fernando M. Paisagens do Sul. Porto Alegre: IEL: IPHAN: IPHAE, 2009a.

DELPHIM, Carlos Fernando M. Viagem às Missões: parecer sobre os sítios de São Miguel Arcanjo, São João Batista e São Lournenço Mártir - Região das Missões/RS. In: DELPHIM, Carlos Fernando M. Paisagens do Sul. Porto Alegre: IEL: IPHAN: IPHAE, 2009b.

FERNÁNDEZ CACHO, Silvia. et al. Paisaje y Patrimonio Cultural en Andalucía: tiempo, usos e imágenes. Sevilla: Instituto Andaluz del Patrimonio Histórico, Junta de Andalucía, 2010.

FERNÁNDEZ CACHO, Silvia. et al. Registro de paisajes de interés cultural de Andalucía: documento divulgativo. Sevilla: Consejería de Cultura, 2018.

FIGUEIREDO, Vanessa. O patrimônio e as paisagens: novos conceitos para velhas concepções? Paisagem e Ambiente, n. 32, p. 83-118, 27 dez. 2013.

FREIRE, Beatriz Muniz; MEIRA, Ana Lúcia G. A Tava e o reconhecimento do Guarani em seu território tradicional. In: VIÑUALES, Graciela M. (org.). Territorio, poblamiento y ciencia en las Missiones Jesuíticas de Guaraníes. Buenos Aires: CEDODAL, 2019.

GUTIERREZ, Ramón (dir). Las Missiones Jesuíticas de la Região

Guaranítica: uma experiencia cultural y social americana. Buenos Aires: CEDODAL, 2013.

HISTÓRIA. In: Prefeitura Municipal de São Borja. São Borja, 6 jul. 2017a..

HISTÓRIA. In: Prefeitura de São Miguel das Missões. São Miguel das Missões, 9 mai. 2017 b.

INSTITUTO DO PATRIMÔNIO HISTÓRICO E ARTÍSTICO NACIONAL (IPHAN). Os sambas, as rodas, os bumbas, os meus e os bois: a trajetória da salvaguarda do patrimônio cultural imaterial no Brasil. 2. ed. Brasília: IPHAN, 2006.

INSTITUTO DO PATRIMÔNIO HISTÓRICO E ARTÍSTICO NACIONAL (IPHAN). Portaria $\mathbf{n}^{\circ}$ 127, de 30 de abril de 2009. Estabelece a Chancela da Paisagem Cultural. Brasília, Diário Oficial da União, 5 mai. 2009, p. 17. 
INSTITUTO DO PATRIMÔNIO HISTÓRICO E ARTÍSTICO NACIONAL (IPHAN). Ata da $67^{a}$ Reunião do Conselho Consultivo do Patrimônio Cultural. Brasília, 3 mai. 2011.

KERN, Arno Alvarez. Do pré-urbano ao urbano: a cidade missioneira colonial e seu território. Cadernos IHU Ideias, São Leopoldo, n. 80, ano5, 2007.

MARCHI, Darlan de M. O patrimônio antes do patrimônio em São Miguel das Missões: dos jesuítas à Unesco. 2018. Tese (Doutorado em Memória Social e Patrimônio Cultural) - Programa de Pós-Graduação em Memória Social e Patrimônio Cultural, Universidade Federal de Pelotas, Pelotas, 2018.

MEIRA, Ana Lúcia G. O patrimônio histórico e artístico nacional no Rio Grande do Sul no século XX: atribuição de valores e critérios de intervenção. 2008. Tese (Doutorado em Planejamento Urbano e Regional) - Programa de Pós-Graduação em Planejamento Urbano e Regional, Universidade Federal do Rio Grande do Sul, Porto Alegre, 2008.

MEIRA, Ana Lúcia G. Das pedras aos lambrequins: a preservação do patrimônio arquitetônico e urbano no Rio Grande do Sul do século XX. São Leopoldo: Ed. Unisinos, 2019.

ORGANIZAÇÃO das Nações Unidas para a Educação, a Ciência e a Cultura (Unesco). Textos base: Convenção de 2003 para a Salvaguarda do Patrimônio Cultural Imaterial. [Brasília], Unesco-Brasil, 2014.

PAEZ, Tereza. Prefácio. In: CARVALHO, Aline; MENEGUELLO, Cristina (org.). Dicionário Temático de Patrimônio. Campinas: Ed. Unicamp, 2020. p.15-21.

PEREIRA, Fernanda. Lugar de referência para o povo Guarani é reconhecido como Patrimônio Cultural do MERCOSUL. PORTAL Iphan. Brasília, 2018.

POSSAMAI, Zita (org.). A memória cultural numa cidade democrática. Porto Alegre: SMC, 2001.

RIBEIRO, Cleodes M. P.; POZENATO, José Clemente. Projeto ECIRS: guardião de uma cultura. In: RIBEIRO, Cleodes M.P.; POZENATO, José Clemente. (org.) Cultura, imigração e memória: percursos e horizontes. Caxias do Sul: EDUCS, 2004.

RIBEIRO, Rafael Winter. Paisagem cultural. In: CARVALHO, Aline; MENEGUEllo, Cristina (org.). Dicionário Temático de Patrimônio. Campinas: Ed. Unicamp, 2020.

RIBEIRO, Rafael Winter. Paisagem Cultural e Patrimônio. Rio de Janeiro: IPHAN/COPEDOC, 2007. 
RIO GRANDE DO SUL. Secretaria de Educação e Cultura. Carta Cultural de São Miguel das Missões. Porto Alegre: SEC, Conselho Estadual de Cultura, [1974?].

SALMERÓN ESCOBAR, Pedro. Guia del Paisaje Cultural para el Desarrollo Sostenible del Territorio de las Misiones Guaranies de Brasil (2005-2008). Sevilha: IAPH, 2008.

SANT'ANNA, Márcia (org.). Registro do patrimônio imaterial. Brasília: IPHAN, 2002.

SCHMITZ, Pedro Ignácio et al. A grande estância da Redução de Yapeyu: resultados preliminares de um projeto de pesquisa. In: FLECK, Eliane Cristina D.; ROGGE, Jairo Henrique. A ação global da Companhia de Jesus: embaixada política e mediação cultural. São Leopoldo: Oikos, 2018.

SILVA, Luis Cláudio da. Parque das Missões - uma proposta para o desenvolvimento sustentável da região: cultura, natureza e turismo. 1997. Trabalho de Conclusão (Especialista em Ciências Ambientais) - Curso de PostGrado em Formación Ambiental, Facultad Latinoamericana de Ciencias Ambientales, La Plata, 1997.

SOUZA, José Otávio Catafesto de et al. Tava Miri São Miguel Arcanjo, Sagrada Aldeia de Pedra: os M'Byá-Guarani nas Missões. Porto Alegre: IPHAN, 2007.

SOUZA FILHO, Carlos F. Marés de. Bens culturais e sua proteção jurídica. 3.ed. Curitiba: Juruá, 2006.

STELLO, Vladimir Fernando. Sítio arqueológico de São Miguel Arcanjo: avaliação conceitual das intervenções: 1925-1927 e 1938-1940. Porto Alegre: UFRGS, 2005. Dissertação (Mestrado em Engenharia) - Faculdade de Engenharia, Universidade Federal do Rio Grande do Sul, Porto Alegre, 2005.

STELLO, Vladimir Fernando. Além das reduções: a paisagem cultural da região missioneira. Tese (Doutorado em Planejamento Urbano e Regional) Programa de Planejamento Urbano e Regional, Universidade Federal do Rio Grande do Sul, Porto Alegre, 2013.

SUSTERSIC, Darko B. La historia de las imágenes misioneras: 1610-1768. In: GUTIERREZ, Ramón (dir). Las Missiones Jesuíticas de la Região Guaranítica: uma experiencia cultural y social americana. Buenos Aires: CEDODAL, 2013. p. 41-48.

VARGAS, José Afonso de; SCHMITZ, Pedro Inácio. O Posto do Aferidor da grande estância missioneira de Yapeyu. Revista do CEPA, Santa Cruz do Sul, n. 43 , v. 31, p. 1-17, 2015. 


\title{
Remnants of the Jesuit-Guarani Missions in Rio Grande do Sul: from stone and lime to the cultural landscape
}

\begin{abstract}
The tangible and intangible heritage of the Jesuit-Guarani Missions, symbolized by the ruins of São Miguel Arcanjo, received all forms of heritage acknowledgment throughout the $20^{\mathrm{th}}$ and $21^{\text {st }}$ centuries: Historical Monument at the state level, National historical and artistic heritage, World heritage, Cultural heritage of Brazil, Cultural heritage of Mercosur and also an indirect association to the title of Brazilian cultural reference. This article aims at reflecting on the scope of the process of making the mission remnants a heritage based on bibliographic review, proposing a periodization in three components: the traditional approach related to tangible heritage, the approach related to intangible heritage, and the territorial approach, which comprises the remnants as a system - the missionary cultural landscape. This concept was the basis for the project of the Cultural Landscape Guide for Sustainable Development of Missions, the result of international cooperation between Brazil and Spain. The research performed to prepare the Guide identified hundreds of cultural and natural heritages of interest for preservation, in addition to the remnants of the old reductions. Heritages that were built by new agents, such as immigrants who arrived in the $19^{\text {th }}$ century. These contributions are consistent with the concept of cultural landscape, which, due to its extent, brought together several missionary cities around the project for appreciation of a territory, in addition to presupposing dialogue between different social groups. Although the execution of the Guide was still unfinished, it resulted in the creation of the National historical park of Missions and provided an important theoretical and practical contribution to the Brazilian institutions that participated in the process.
\end{abstract}

Keywords: Jesuit-Guarani Missions. Tava. Intangible cultural heritage. Cultural landscape.

Recebido: 09/08/2020

Aceito: $24 / 08 / 2020$

\section{Declaração de autoria}

Concepção e elaboração do estudo: Meira, Ana Lúcia G.

Coleta de dados: Meira, Ana Lúcia G.; SILVA, Leonardo Alberto Cora

Análise e discussão de dados: Meira, Ana Lúcia G.; SILVA, Leonardo Alberto

Cora

Redação: Meira, Ana Lúcia G. 
Revisão crítica do manuscrito: Meira, Ana Lúcia G.; SILVA, Leonardo Alberto Cora

\section{Como citar}

MEIRA, Ana Lúcia G. SILVA, Leonardo Alberto Cora. Remanescentes das Missões Jesuítico-Guaraní no Rio Grande do Sul: da pedra e cal à paisagem cultural. Em Questão, Porto Alegre, v 26, p. 68-92, Edição Especial Dossiê Patrimônio e Culturas Tradicionais, 2020. DOI: http://dx.doi.org/10.19132/1808-5245260.68-92

${ }^{1}$ Fazem parte da Associação dos Municípios das Missões (AMM) os seguintes municípios: Bossoroca, Caibaté, Cerro Largo, Dezesseis de Novembro, Entre-Ijuís, Eugênio de Castro, Garruchos, Giruá, Guarani das Missões, Mato Queimado, Pirapó, Porto Xavier, Rolador, Roque Gonzales, Salvador das Missões, Santo Ângelo, Santo Antônio das Missões, São Borja, São Luiz Gonzaga, São Miguel das Missões, São Nicolau, São Paulo das Missões, São Pedro do Butiá, Sete de Setembro, Ubiretama e Vitória das Missões. Segundo Izabél Cristina Ribas, assessora de imprensa da AMM, o município de São Borja foi incorporado à AMM a partir do trabalho conjunto entre IPHAN e IAPH sobre a paisagem cultural das Missões.

${ }^{2}$ Esta adjetivação restringe seu sentido por se referir a apenas a um dos sentidos humanos - o tato.

3 A Administração Popular, em Porto Alegre, foi uma coalizão de partidos políticos liderados pelo Partido dos Trabalhadores (PT), que governou a cidade entre 1989 e 2002. Promoveu e ampliou espaços de participação cidadã como o Orçamento Participativo. Particularmente, interessam aqui aqueles relacionados com o tema do patrimônio e da memória cultural.

${ }^{4}$ As discussões sobre o assunto giravam em torno do bem a ser preservado: a sede alugada onde o grupo vivia e atuava - a Terreira da Tribo - ou o grupo em si - o Ói Nóis Aqui Traveiz. O tombamento do bem material garantiria, por si só, a relevante atuação do grupo na cultura da cidade?

5 Participaram do Seminário importantes profissionais e estudiosos dos temas relacionados à memória e ao patrimônio cultural como Ulpiano Bezerra de Menezes da Universidade de São Paulo (USP), Carlos Marés de Souza Filho da Pontifícia Universidade Católica do Paraná (PUC-PR), Ruben Oliven e Ana Luiza Rocha da Universidade Federal do Rio Grande do Sul (UFRGS) e Cyro de Oliveira Lyra do IPHAN.

${ }^{6}$ No âmbito federal, é reconhecido que as primeiras referências a manifestações culturais já estavam presentes no anteprojeto que Mário de Andrade apresentou, nos anos 1930, para subsidiar a legislação federal sobre a preservação do patrimônio cultural (IPHAN, 2006). No entanto, em sua versão final - o Decreto-Lei $n^{\circ}$ 25/1937, a lei que instituiu o IPHAN, privilegiou-se a proteção do patrimônio material por meio do instituto do tombamento. Os temas relacionados à dinâmica cultural foram incorporados nas políticas públicas a partir da criação do Centro Nacional de Referência Cultural (CNRC), em 1975, que facilitou a ampliação de conceitos presente na Constituição do Brasil de 1988 (FONSECA, 2005). Posteriormente absorvido pelo IPHAN, o CNRC se tornou o embrião dos setores que passaram a se ocupar do patrimônio imaterial na Instituição.

${ }^{7}$ O Talian é uma mescla da fala dialetal dos imigrantes de várias regiões da Itália, que passaram a conviver na serra gaúcha e catarinense, e que incorporou palavras de várias origens.

${ }^{8}$ O Ofício das Baianas do Acarajé, a Roda de Capoeira e o Ofício dos Mestres de Capoeira tiveram seus inventários iniciados em outros estados, mas a abrangência é nacional.

${ }^{9}$ O registro das Lendas urbanas como patrimônio imaterial, em Porto Alegre, foi informado pela EPAHC. Os locais que remetem a histórias de crimes, punições, reclusão, ainda hoje narradas 
já foram temas do projeto Viva o Centro a Pé, realizado pela Prefeitura Municipal de Porto Alegre.

${ }^{10}$ A maioria das instituições de preservação, no Brasil, nos três níveis de governo, vem sendo esvaziada gradualmente, devido à ausência de concursos públicos, falta de recursos técnicos e financeiros, e nomeação de gestores que desconhecem o tema.

${ }^{11} \mathrm{O}$ evento foi organizado pela Prefeitura Municipal de Bagé, IPHAN, IPHAE, Universidade Federal do Pampa (UniPampa), Universidade Federal de Pelotas (UFPel) e Universidade Regional da Campanha (URCamp). A referência a essas instituições é relevante para mostrar que participaram da discussão dos princípios da Carta representantes dos âmbitos municipal, estadual e federal, bem como instituições de ensino e pesquisa, institutos de preservação e órgãos da administração municipal.

12 O IAPH foi criado em 1989, ligado ao Conselho de Cultura da Andaluzia, e realiza investigação, documentação, conservação, restauração, formação técnica e difusão do patrimônio.

${ }^{13}$ Cabe esclarecer que nessa época o Brasil já trabalhava com a candidatura do Rio de Janeiro para Patrimônio mundial. Em 2003, houve a sugestão do seu enquadramento como Paisagem Cultural mas, somente em 2012, o Rio de Janeiro: paisagens cariocas entre a montanha e o mar foi declarado Patrimônio mundial. O dossiê sofreu modificações durante quase uma década, adaptando-se às exigências da Unesco devido à especificidade do sítio.

${ }^{14} \mathrm{O}$ Registro funciona como um inventário do território andaluz, tomando como base o mapa fisionômico das paisagens. A existência prévia de mapas cartográficos confiáveis é essencial. No Brasil é difícil ter levantamentos detalhados em muitas regiões, sendo que muitas vezes se recorre aos conhecidos mapas do Exército.

15 Nos estudos de áreas urbanas, como na cidade de Sevilha, o IAPH se refere a Paisagem histórica urbana como forma de manifestação urbana da paisagem cultural, coerente com orientação da Unesco. No Brasil, o IPHAN se manifestou contrário à terminologia, por entender que o adjetivo cultural já confere à paisagem um sentido amplo, não sendo necessária uma nova distinção (FIGUEIREDO, 2013).

16 Tendo em vista a abrangência dos estudos realizados e sua importância para a região, atualmente, é de se lamentar que o acesso aos levantamentos não seja facilitado tanto no sítio do IPHAN quanto da URI.

${ }^{17}$ É interessante citar que, poucos anos antes, houve uma proposta semelhante, que recebeu a caracterização de "parque em constelação", mas que não serviu de base para essa proposta do Parque Histórico, embora haja semelhanças. Chamado de Parque das missões, foi desenvolvido pelo diretor do Museu das Missões entre 1993 e 1998 - Luis Cláudio da Silva. Pela sua formação em engenharia florestal, o enfoque maior da proposta se referia ao patrimônio natural botânico da região, englobando as comunidades locais e, particularmente, os guaranis (SILVA, 1997).

${ }^{18}$ Em função disso, o projeto de lei não prosperou na Câmara dos Deputados e o Parque histórico nacional das Missões não foi regulamentado até hoje. 